\title{
SUINOCULTURA DE SUBSISTENNCIA COMO ALTERNATIVA DE GERAÇÃO DE RENDA NO SERTÃO PARAIBANO: UM ESTUDO DE CASO
}

\author{
SUBSISTENCE SUINCULTURE AS AN INCOME GENERATION ALTERNATIVE IN \\ THE SERTÃO OF PARAÍBA: A CASE STUDY
}

LA SUINCULTURA DE SUBSISTENCIA COMO UNA ALTERNATIVA DE GENERACIÓN DE INGRESOS EN LAS SERTÃO DE PARAÍBA: UN ESTUDIO DE CASO

José Jaciel Ferreira dos Santos ${ }^{1}$, Valéria Fernandes de Oliveira Sousa ${ }^{2 *}$, Michel Douglas Santos Ribeiro ${ }^{3}$, Rosilene Agra da Silva ${ }^{4}$, Cizia Fabiana Mouta Almeida De Queiroga ${ }^{4}$, Mailson Gregório Gonçalves ${ }^{5}$, Izaias Romário Soares Do Nascimento ${ }^{2}$

${ }^{1}$ Secretaria de Agricultura e Pesca de Caxias, Prefeitura Municipal de Caxias, Caxias-MA, Brasil.

${ }^{2}$ Programa de Pós Graduação em Agronomia, Universidade Federal da Paraíba (UFPB), Areia-PB, Brasil.

${ }^{3}$ Programa de Pós Graduação em Fitotecnia, Universidade Federal do Ceará (UFC), Fortaleza-CE, Brasil.

${ }^{4}$ Programa de Pós Graduação em Sistemas Agroindustriais, Universidade Federal de Campina Grande (UFCG), Pombal-PB, Brasil.

${ }^{5}$ Programa de Pós Graduação em Engenharia Agrícola, Universidade Federal de Campina Grande (UFCG),

Campina Grande-PB, Brasil.

*Correspondência: Programa de Pós Graduação em Agronomia, Universidade Federal da Paraíba, Campus II, Rodovia PB-079, Areia, Paraíba, Brasil.CEP:58.397-000.e-mail valeriafernandesbds@ gmail.com

Artigo recebido em 20/04/2020 aprovado em 03/11/2020 publicado em 05/03/2021.

\section{RESUMO}

No Nordeste é habitual suinocultura de subsistência, porém, sabe-se pouco sobre aspectos socioeconômicos. Objetivou-se avaliar a importância socioeconômica da criação de suínos para criadores urbanos, bem como analisar o manejo empregado e os impactos que uma criação extensiva de animais pode causar. A pesquisa foi desenvolvida no município de Pombal, Paraíba, aplicando um questionário semiestruturado para 55 produtores de suínos da região. Os dados obtidos foram utilizados para traçar o perfil socioeconômico e ambiental das produções. Observou-se que a faixa etária dos criadores varia de 25 a 63 anos, $71,8 \%$ são do sexo masculino e $28,2 \%$ do sexo feminino, 44,7\% são analfabetos ou semianalfabetos. O tempo médio de criação de suínos é de 2 a 4 anos, 61,73\% dos criadores fornecem restos de comida como única alimentação. Quanto às dejeções dos suínos, não existe manejo adequado em $100 \%$ das instalações, prejudicando as propriedades químicas e biológicas do solo e da água. A falta de assistência técnica e de políticas públicas eficazes faz com que a criação de suínos se torne uma ameaça ao meio ambiente e a própria saúde. Portanto, a infraestrutura da pocilga comunitária dos criadores de suínos de Pombal-PB não atende aos requisitos mínimos de bem estar animal.

Palavras-chave: Impactos ambientais, suinocultura, viabilidade socioeconômica.

\section{ABSTRACT}

In the Northeast, subsistence pig farming is usual, however, little is known about socioeconomic aspects. The objective was to evaluate the socioeconomic importance of pig breeding for urban breeders, as well as to analyze the management used and the impacts that extensive animal breeding can cause. The research was carried out in the municipality of Pombal, Paraíba, using a semi-structured questionnaire for 55 pig producers in the region. The data obtained were used to trace the socioeconomic and environmental profile of the productions. It was observed that 
the age group of the breeders varies from 25 to 63 years, $71.8 \%$ are male and $28.2 \%$ female, $44.7 \%$ are illiterate or semi-literate. The average pig breeding time is 2 to 4 years, $61.73 \%$ of the breeders provide leftover food as a single feed. As for swine dejections, there is no adequate management in 100\% of the facilities, damaging the chemical and biological properties of the soil and water. The lack of technical assistance and effective public policies makes pig farming a threat to the environment and health itself. Therefore, the infrastructure of the community pigsty for pig farmers in Pombal-PB does not meet the minimum animal welfare requirements.

Keywords: Environmental impacts, pig farming, socioeconomic viability.

\section{RESUMEN}

En el noreste, la cría de cerdos de subsistencia es habitual, sin embargo, se sabe poco sobre aspectos socioeconómicos. El objetivo era evaluar la importancia socioeconómica de la cría de cerdos para los criadores urbanos, así como analizar el manejo utilizado y los impactos que puede causar la cría extensiva de animales. La investigación se llevó a cabo en el municipio de Pombal, Paraíba, utilizando un cuestionario semiestructurado para 55 productores de cerdos en la región. Los datos obtenidos se utilizaron para rastrear el perfil socioeconómico y ambiental de las producciones. Se observó que el grupo de edad de los criadores varía de 25 a 63 años, el 71.8\% son hombres y el $28.2 \%$ mujeres, el $44.7 \%$ son analfabetos o semianalfabetos. El tiempo promedio de cría de cerdos es de 2 a 4 años, el 61,73\% de los criadores proporcionan los restos de comida como un solo alimento. En cuanto a las abandonos porcinos, no existe un manejo adecuado en el 100\% de las instalaciones, dañando las propiedades químicas y biológicas del suelo y el agua. La falta de asistencia técnica y políticas públicas efectivas hacen que la cría de cerdos sea una amenaza para el medio ambiente y la salud misma. Por lo tanto, la infraestructura de la pocilga comunitaria para los criadores de cerdos en Pombal-PB no cumple con los requisitos mínimos de bienestar animal.

Descriptores: Impactos ambientales, cría de cerdos, viabilidad socioeconómica.

\section{INTRODUÇÃO}

O Brasil é um dos maiores produtores mundiais de alimentos e a suinocultura brasileira vem crescendo vigorosamente nas ultimas décadas, fruto dos investimentos em ampliações, como também de uma substancial evolução na produtividade dos criadouros, onde neste período houve significativa expansão da suinocultura, além de diversas aquisições e fusões que mudaram a produção no país (ZANELLA;MORÉS; BARCELLOS, 2017).

A carne suína é uma das fontes de proteína animal mais importante. Segundo dados do IBGE (2018) o Brasil é o quarto maior produtor e exportador de carne suína do mundo, com produção nacional no último trimestre de 2017 de $987.570 .643 \mathrm{Kg}$, dando à suinocultura uma posição de destaque no agronegócio nacional, no entanto, surge nesse momento uma preocupação quanto ao modelo de organização deste tipo de produção agrícola e seus impactos ambientais e até na saúde da população (BROETTO et al., 2015).
O Brasil possui as melhores condições para o aumento da criação de suínos, dentre elas o clima tropical, mão-de-obra de baixo custo, facilidade para manejo e tratamento de dejetos pelas grandes dimensões territoriais, topografia plana, grande produção de grãos (milho e soja), dentre outros (FRAGA; CAVATORTA; GONÇALVES, 2017). Entretanto, a suinocultura possui constantes desafios relacionados à exploração do potencial do animal, dentre eles, o conforto térmico (pois apesar de um clima propicio para criação, possui estações e regiões muito quentes) dificultando o bem estar dos animais (CECCHIN et al., 2016).

A heterogeneidade da forma da criação de suínos no Brasil ainda é uma das grandes preocupações para a indústria, sendo nas regiões Sul e Sudeste, bastante tecnificada e rústica no Norte e Nordeste do país, em que os estabelecimentos agropecuários produzem para subsistência familiar, os quais ainda são 
apontados de impedir a melhoria da atividade na região (SILVA FILHA et al. 2011).

Esta suinocultura de subsistência é caracterizada pela inserção de pequenos produtores, geralmente oriundos da agricultura familiar, sendo forma marginal na cadeia produtiva de carne suína e voltada para o auto consumo com baixo nível tecnológico (SANTOS et al., 2016).

Muitas famílias brasileiras dependem diretamente de espécies animais locais e da biodiversidade do ecossistema para os seus sustentos. Mas o que define as características do manejo da produção adotado é basicamente o capital disponível do produtor. Para Carvalho e Viana (2011) os sistemas de exploração de suínos são definidos de acordo com o tipo de manejo adotado, sendo desta forma classificados em 4 tipos: Sistema Extensivo ou a Solta, Sistema Semiextensivo, Sistema Intensivo de Suínos Criados Ao Ar Livre (SISCAL) e ainda como Sistema Intensivo de Suínos Confinados (SISCON).

Quando se trata do agronegócio na região Nordeste em relação à suinocultura, percebe-se que a maioria dos criadores visa apenas destino final da carne suína para o comércio local ou próprio consumo, infelizmente, indicando assim, um baixo gasto com mecanização, o que de fato é característica da atividade nessa região, composta por propriedades de pequeno porte, devido à falta de capital e ao baixo investimento em tecnologia (FEHR, 2017). Fora os problemas fitossanitários causados pela criação de subsistência sem manejo sanitário adequado.

Com isso, há necessidade de fazer um estudo de caso sobre a realidade vivida por estes criadores, com a intenção de propor soluções estratégicas para resolução da maioria dos problemas e incentivar a criação de políticas públicas voltadas à assistência técnicas para população. Sendo assim, o presente trabalho teve como objetivo avaliar os principais problemas levantados e apontar para estes criadores os requisitos mínimos de produção de alimentos seguros, pois estes animais são comercializados nos diversos estabelecimentos da cidade, e segundo informações fornecidas, esta atividade constitui uma importante fonte de renda para a maioria dos criadores de suínos.

\section{MATERIAIS E MÉTODOS}

O estudo foi desenvolvido no município de Pombal - PB, município localizado no sertão paraibano, com as coordenadas geográficas de latitude (6 46' 8', S) e longitude ( $\left.37^{\circ} 47^{\prime} 45^{\prime \prime} \mathrm{O}\right)$. O clima da região caracteriza-se como quente e seco (semiárido), com temperaturas entre $18^{\circ} \mathrm{C}$ e $39^{\circ} \mathrm{C}$, com uma média de precipitações pluviométrica anual de $700 \mathrm{~mm}$. A economia da cidade é dominada pela agricultura a pecuária, o comércio interno e poucas fábricas (LACERDA et al., 2013).

A pesquisa foi desenvolvida em uma pocilga comunitária de uma área cedida pela Prefeitura Municipal local, onde 55 famílias de criadores de suínos dividem o espaço em instalações precárias, mal planejadas e sem a mínima infraestrutura básica, onde um grande número de animais é criado sem atender os critérios da biosseguridade animal.

A suinocultura existente na cidade de Pombal sem qualquer infraestrutura básica, possui bacias de barro, chão batido e lama, alimentador e alimentação inadequadas divisão com grade em ferro, cobertura baixa com palha ou algumas telhas de barro, nenhum controle sanitário, sem água e ainda outros animais circulando junto aos suínos (Figura 1).

A primeira etapa para execução deste estudo foi visitar a pocilga pública para conhecer a realidade dos produtores. Na visita, observou-se que esta não possui qualquer estrutura física ou ambiental e 
possibilitou o contato com alguns criadores que se interessaram a ajudar na elaboração desse estudo.

Figura 1. Estrutura da pocilga comunitária na cidade de Pombal - PB, 2017.

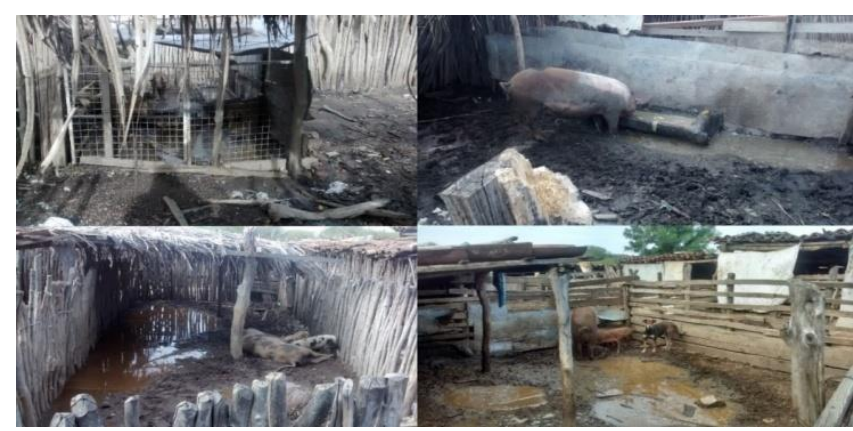

Fonte: Autoria própria.

Em seguida, fez-se uma pesquisa bibliográfica sobre a atividade da suinocultura e suas formas de implantação. Foram utilizados livros, artigos de periódicos e documentos referentes ao assunto. Também foi realizada uma visita técnica a suinocultura do IFPB na cidade de São Gonçalo - PB. Nesta visita, juntamente com criadores, observou-se a estrutura física da edificação, como também o seu funcionamento. Essa suinocultura possui uma estrutura satisfatória para a criação dos animais, servindo de modelo para o presente estudo.

As atividades foram desenvolvidas através de visitas in locus com as 55 famílias durante o mês de Outubro no ano de 2017, em que representantes destas famílias participaram da pesquisa,aplicando-se questionário semiestruturado com a intenção de se obter informações quanto à principal atividade econômica, o manejo utilizado, as condições higiênicas de trabalho, tipo de alimentação fornecida e a presença ou a ausência de assistência técnica.

A metodologia utilizada foi a de Levin (1987), baseada na estimativa da proporção populacional. Os procedimentos empregados para determinação da equação matemática que permitiu o cálculo da amostra (n) a partir da estimativa da proporção populacional foram determinados pelos seguintes critérios: a. Populações finitas; b. Grau de confiança 95\%; c. Nível de significância $\alpha$ de 0,05 . A equação estatística utilizada no cálculo na determinação do tamanho da amostra pesquisada encontra-se exposta abaixo (Equação 1).

$$
n=\frac{N \cdot p \cdot q \cdot\left(\frac{Z \alpha}{2}\right)^{2}}{p \cdot q \cdot\left(\frac{Z \alpha}{2}\right)^{2}+(N-1) \cdot E^{2}}
$$

Onde:

n: é a quantidade de indivíduos que se pretende calcular;

N: é o tamanho da população; $Z \alpha / 2$ é o valor crítico que corresponde o grau de confiança desejado;

p: é a proporção populacional de indivíduos que pertencem à categoria de interesse no estudo $=0,5$;

q: corresponde a quantidade de indivíduos que não participa do grupo pesquisado $(q=1-p)=0,5$;

E: é a Margem de erro.

Como $\mathrm{p}$ era desconhecido considerou-se a relação do produto $\mathrm{p} \cdot \mathrm{q}=0,25$, que é o maior valor que pode ser alcançado por essa relação p.q (LEVINE, 2000).

Os dados foram tabulados em planilhas eletrônicos do Microsoft Excel 2010 e confeccionados os gráficos e tabelas.

\section{RESULTADOS E DISCUSSÃO}

A criação de suínos no município de Pombal PB é uma prática bastante antiga, onde há uma criação coletiva na periferia da cidade, sendo uma das formas de geração de renda mais viáveis para boa parte dessa população. Porém, com o crescimento populacional e consequentemente expansão da zona urbana, houve a necessidade de alocação destes criadores. 
Logo, a prefeitura municipal conseguiu um terreno a cerca de $500 \mathrm{~m}$ do antigo local, e desta forma propiciar aos criadores de suínos uma área adequada para instalação de uma suinocultura coletiva. Mas um fato importante observado neste trabalho é que o terreno onde os animais são criados não é de posse de nenhum criador, sendo um imóvel da prefeitura "emprestado" para a criação. Com esta justificativa, $100 \%$ dos criadores afirmaram não investir na infraestrutura da pocilga, como pode ser observado na Figura 2, para não perderem o investimento futuramente.

A partir deste trabalho, constatou-se que $71,8 \%$ dos produtores são do sexo masculino enquanto $28,2 \%$ do sexo feminino. Quanto à escolaridade, como mostrado na Tabela 1, observou-se que $43,6 \%$ são analfabeto ou semianalfabeto, ou seja, 24 pessoas dos 55 entrevistados, entre homens e mulheres criadores de suínos que não têm escolaridade, o que se apresenta como um dado de grande importância, pois isso dificulta a busca por mais oportunidades, refletindo diretamente de maneira negativa no desenvolvimento do grupo como um todo. E apenas 5,4\% têm ensino médio completo, representando um percentual muito baixo para a comunidade. Do total da população estudada $46,2 \%$ responderam saber ler e escrever, o restante afirmou ter muita dificuldade.

Figura 2. Vista panorâmica da Pocilga. Pombal-PB, 2017.

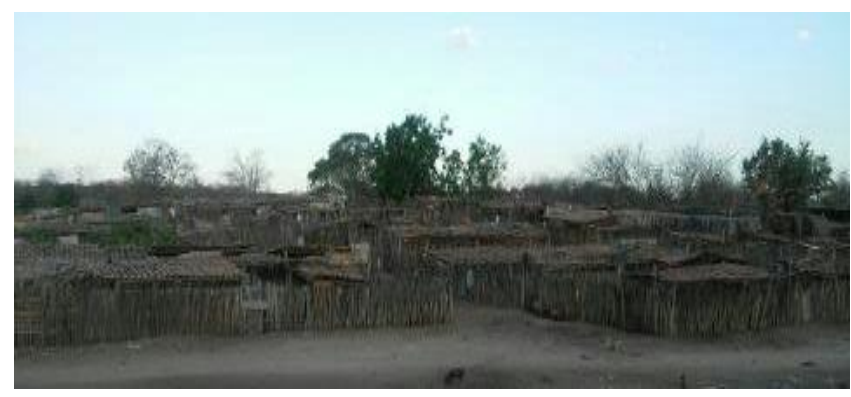

Fonte: Autoria própia.

Tabela 1. Nível de escolaridade dos criadores urbanos de suínos do município de Pombal - PB.

\begin{tabular}{lcc}
\hline \multicolumn{1}{c}{ Escolaridade } & Valor absoluto & Percentual \\
\hline Semianalfabeto & 24 & $43,6 \%$ \\
Fundamental Incompleto & 15 & $27,2 \%$ \\
Fundamental Completo & 8 & $14,5 \%$ \\
Médio Incompleto & 5 & $9,1 \%$ \\
Médio Completo & 3 & $5,4 \%$ \\
Superior & 0 & $0 \%$ \\
\hline Total & 55 & $100 \%$
\end{tabular}

Fonte: Dados da pesquisa (2017).

De acordo com Rocha et al. (2016) o nível de escolaridade entre os produtores de suínos é baixo, consequente da maioria desses produtores periurbanos serem oriundos da zona rural, acarretando baixa escolaridade em razão da falta de escolas rurais, da dificuldade de percorrer grandes distâncias até a cidade, onde seria possível ter acesso ao estudo, e os pais necessitavam que os filhos ajudassem nas 
atividades do campo, sendo os fatores que contribuem ao baixo índice.

Com relação ao tempo que atuavam na criação de animais, especialmente suínos, $87 \%$ afirmaram criar esses animais entre 2 e 4 anos, $8 \%$ criam a menos de 2 anos e apenas 5\% criam a mais de 4 anos, sendo que o criador com mais tempo no ramo argumentou trabalhar com suínos a aproximadamente 10 anos (Figura 3).

Figura 3. Tempo de atuação na suinocultura. Pombal-PB, 2017.

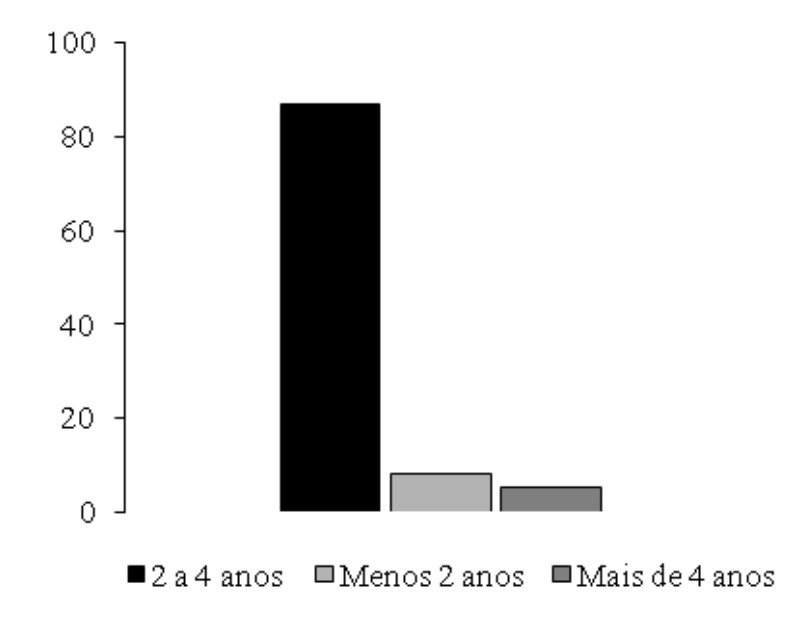

A criação de suínos para esta comunidade é de suma importância, sendo o meio de geração de renda mais importante para todos os criadores, isto porque quase nenhuma família apontou a criação como hobby ou somente por amor à profissão, entretanto também, esta não é a única forma de renda da família nem tão pouco é vista pela maioria dos criadores como atividade primária. A suinocultura é relevante na geração de renda nos municípios, porém sendo avaliados os setores de produção (criação de suínos) (OLIVEIRA et al., 2016).

Sendo assim, apenas $32 \%$ das famílias entrevistadas têm a suinocultura como única alternativa econômica para a subsistência, apontando na pesquisa a criação desses animais como atividade de importância primária, ou seja, sobrevivem da criação de suínos, sendo esta a única forma de geração de renda. No entanto, $67 \%$ da população de criadores afirmaram ter a suinocultura como atividade de valor secundário, pois faziam outras atividades como a agricultura e pequenos "bicos" (trabalhos autônomos), sendo que nenhuma das famílias tem emprego fixo, tendo à criação de animais maior significância em sua renda. E apenas $1 \%$ afirmou ter prazer em criar os animais, assim como, meio relevante para complementação da renda familiar (Figura 4).

Esses pequenos produtores geralmente utilizam diversificação agrícola, ou seja, à implantação de duas ou mais atividades agropecuárias em uma propriedade rural (SILVA, 2015). O agronegócio nordestino advém da produção agropecuária realizada pelos agricultores familiares. Entretanto, desempenhos desfavoráveis da produção agropecuária são mais intensos no Nordeste, prejudicando a participação do agronegócio total e familiar na Região, possivelmente pela falta de assistência técnica especializada ou 101 própria forma de produção dos animais (GUILHOTO et al., 2014).

Figura 4. Importância econômica da criação de suínos para as famílias entrevistadas. Pombal-PB, 2017.

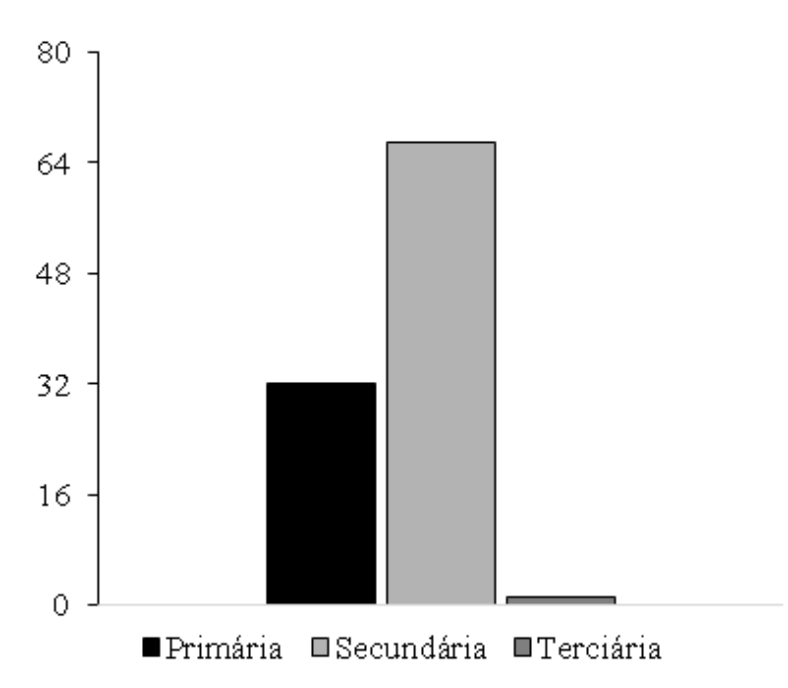

No tocante, ao manejo higiênico-sanitário da alimentação que é fornecida à estes animais, bem como o tipo e a composição, foi observado que $61,73 \%$ dos criadores fornecem restos de comida (lavagem) como única alimentação e o restante $(38,27 \%)$ 
misturam a lavagem com o farelo de trigo, sendo 100\% dos alimentos que são utilizados para alimentação dos animais adquiridos fora da propriedade segundo os próprios criadores (Figura 5).

Figura 5. Tipo de alimentação fornecida para os suínos. Pombal-PB, 2017.

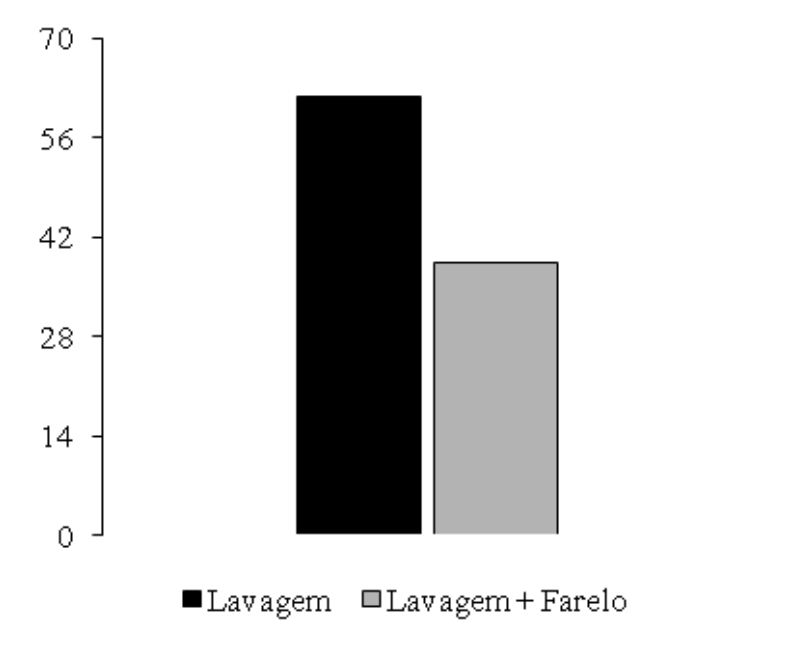

Rocha et al. (2016) e Leite (2014) também constataram uso de lavagem (restos alimentares), bem como o uso associado de lavagem e farelo na suinocultura de subsistência sendo alternativa para baratear o custo, porém usualmente esta lavagem é oriunda de outras localidades, existindo risco de contaminação com patógenos, além da ausência de um manejo alimentar adequado.

Quanto à alimentação e a água servida aos suínos observou-se que a maioria dos criadores não têm nenhum cuidado com a qualidade dos alimentos e tão pouco com a procedência da água. Quando foi investigado sobre a procedência da água utilizada pelos criadores (Figura 6), 76,4\% afirmaram utilizar a água do rio e o restante utilizam água tratada da Companhia de Água e Esgotos da Paraíba (CAGEPA).

De acordo com Leite (2014) analisando caracterização da suinocultura em Mossoró-RN com relação aos aspectos sanitários e riscos de zoonoses foi também diagnosticado que a água oferecida para os animais era de má qualidade higiênico-sanitária, representando risco à saúde, podendo transmitir doenças via fecal-oral. Na Figura 7 é possível observar a precariedade higiênica sanitária no ambiente e na alimentação destes animais.

Figura 6. Fonte de água utilizada pelos criadores. PombalPB, 2017.

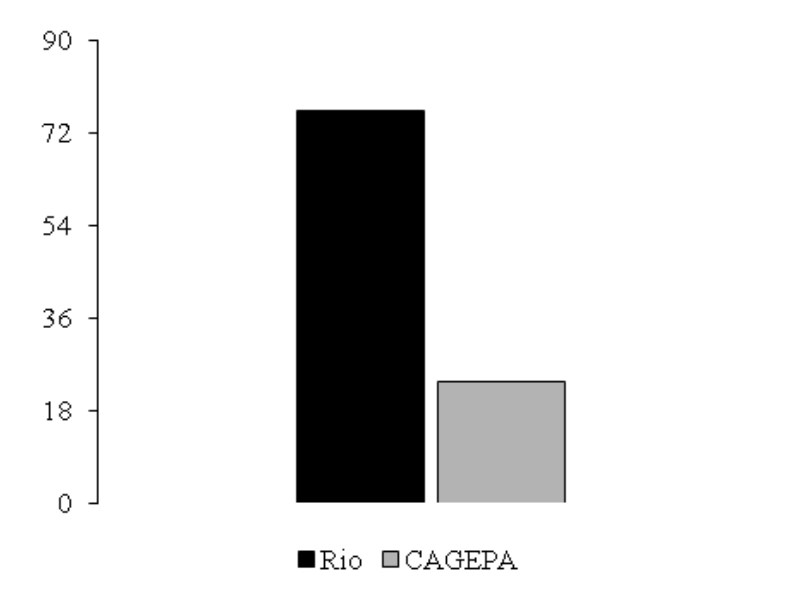

Figura 7. Local de armazenamento da alimentação (Lavagem) e da água dos suínos. Pombal-PB, 2017.

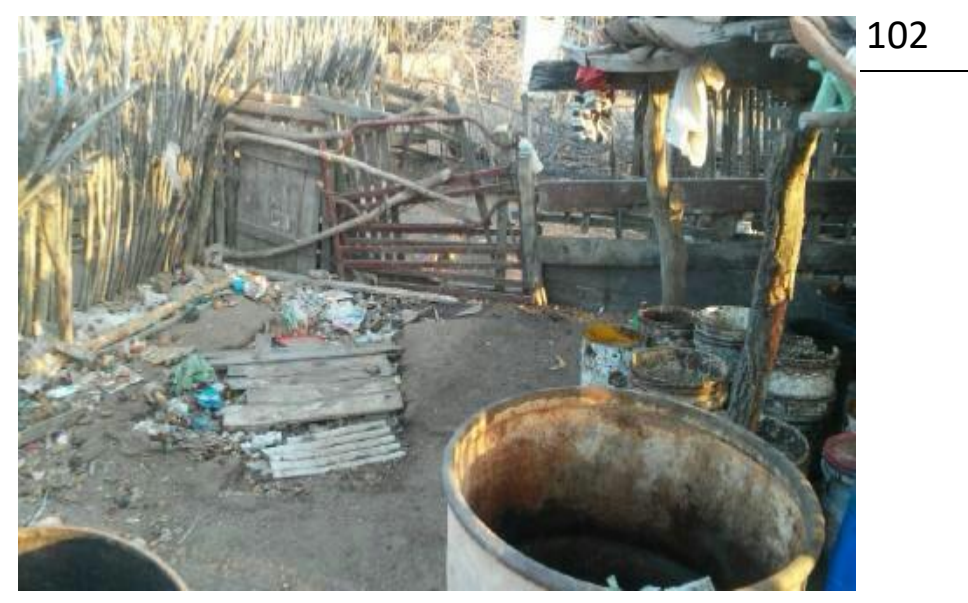

Fonte: Autoria própria.

Com relação à assistência técnica foi observada completa ausência de qualquer auxílio por parte de órgãos públicos com o mesmo sendo observado no que concerne à fiscalização da produção, sendo esta feita sem as condições mínimas de higiene e biosseguridade animal, desta forma os animais são criados de "quaisquer" formas, na medida do que é possível para o pequeno criador. Constatou-se ainda, por meio de observações (nas visitas in lócus) que alguns animais são criados soltos, misturados a outras 
espécies de animais, como: aves, cães, gatos, entre outros. Vários autores demonstram que a suinocultura no Nordeste tem se apresentado de forma incipiente, pouco desenvolvida, em que se vê um grande contingente de animais que são criados de forma primitiva (SILVA FILHA, 2011; LEITE, 2014; SANTOS et al., 2016).

Em 100\% das instalações visitadas não ocorre tratamento algum quanto aos desejos dos suínos, sendo jogados diretamente no solo, isso ocorre tanto pela falta de saneamento básico, como pelo desconhecimento das famílias sobre técnicas de tratamento e reutilização dos dejetos, o que pode ser feito através da compostagem ou utilização de biodigestores, por exemplo, pois quando os dejetos são lançados a céu aberto, diretamente no solo, prejudicam as propriedades químicas e biológicas do solo e da água (processo de eutrofização dos corpos d'água), como a emissão de gases poluentes, dentre eles, amônia, a qual provoca efeitos adversos ao ser humano, como irritação nasal e na pele (ITO; GUIMARÃES; AMARAL， 2016). O Sistema Intensivo de Suínos Criados ao Ar Livre (SISCAL) apresenta-se como alternativa ao sistema confinado e é compatível com o bem estar e com a saúde dos animais isso quando bem manejado é positivo para o ponto de vista ambiental, divergindo das condições deste estudo, pela falta de planejamento (FONTES et al., 2015).

Para um bom planejamento, existem alternativas para manejo, tratamento e destino dos dejetos da suinocultura, as quais são diversas, variando em eficiência e custo de implantação, favorecendo assim, vários métodos de eleição para que os criadores de suínos possam se adequar de acordo com suas necessidades e recursos. Assim, podem-se utilizar as formas de armazenamento de dejetos por esterqueiras e bioesterqueiras que oferecem menor custo de implantação, ou ainda, há a opção de biodigestores, necessitando de maior investimento para a implantação, porém com a vantagem da produção de gás que é convertido em energia e utilizado na própria comunidade (PEROSSI et al., 2017).

Nesta comunidade de criadores eram 100 famílias, atualmente restam cerca de 55, o restante ou desmotivaram-se com a profissão ou não tiveram condições de continuar, o que se sabe é que as famílias que restaram precisam de uma assistência técnica urgente, com capacitações e conscientização, a formação de uma associação entre os criadores para o fortalecimento na busca por melhores condições de trabalho é o próximo passo a ser dado por essa comunidade. A aplicabilidade das políticas públicas de apoio ao pequeno produtor associada à devida assistência técnica é de extrema importância para se construir um modelo de sociedade mais equitativo, que seja ambientalmente sustentável e que tenha a segurança alimentar como eixo estratégico de 103 desenvolvimento.

\section{CONCLUSÃO}

A falta de assistência técnica e de políticas públicas (locais) eficazes, fazem com que a criação de suínos se torne uma ameaça ao meio ambiente e a própria saúde da comunidade.

A infraestrutura da pocilga comunitária dos criadores de suínos de Pombal-PB não atende aos requisitos mínimos de bem estar animal.

A dieta fornecida para os suínos criados não é suficiente em quantidade e qualidade para o desenvolvimento ideal dos animais.

Todos os autores declararam não haver qualquer potencial conflito de interesses referente a este artigo.

\section{REFERÊNCIAS}

BROETTO, T.; TORNQUIST, C.G.; WEBER, E.J.; CAMPOS, B.C.; MERTEN, C.G.; SCHNEIDER, J.C. 
Indicadores geoespaciais para avaliação do impacto ambiental da suinocultura no licenciamento em âmbito municipal. Pesquisa Agropecuária Brasileira, v. 50, n. $12, \quad$ p.1177-1185, 2015. http://dx.doi.org/10.1590/S0100-

204X2015001200007

CARVALHO, P.L.C; VIANA, E. DE F.; Suinocultura SISCAL e SISCON: análise e comparação dos custos de produção. Revista: Custos e @ gronegócio, v. 7, n. 3, p.2-20, 2011.

CECCHIN, D.; CAMPOS, A.T.; SCHIASSI, L.; CRUZ, V.M.F.; SOUSA, F.A. Índice fuzzy para o conforto térmico de suínos na fase de crescimento e terminação com base na temperatura superficial e frequência respiratória. Revista Energia na Agricultura, v. 31, n.4, p.334-341, 2016. http://dx.doi.org/10.17224/EnergAgric.2016v31n4p3 34-341

FEHR, Moreira Bruno Afonso. Análise das variáveis de custos de produção de suínos nas regiões nordeste, centro-oeste, sudeste e sul do Brasil. 2017. 24 p. Trabalho de Conclusão de Curso (Graduação em Ciências Contábeis) - Universidade Federal de Uberlândia, Uberlândia, 2017.

FORTES, A.C.; MORAIS, R.F.; MORAIS, C.S.B.; BARROS, R.P.; CARVALHO, R.O.; COELHO, D.F.O. Implantação de um sistema de criação de suinos ao ar livre (SISCAL) no campus amajari. In: Fórum de Integração Ensino, Pesquisa, Extensão e Inovação Tecnológica do IFRR - e-ISSN 2447-1208, [S.1.], v. 2, n. 1, dez. 2015. Disponível em: $<$ https://periodicos.ifrr.edu.br/index.php/anais_forint/ article/view/396>. Acesso em: 03 mar. 2018.

FRAGA, N.C.; CAVATORTA, M.G.; GONÇALVES, C. Tropeiros de porcos: a importância dos porcadeiros e da suinocultura na formação socioespacial de Pitanga (PR). Revista Tamoios, v.13, n. $1, \quad$ p.72-84, $2017 . \quad$ Doi: 10.12957/tamoios.2017.25257

GUILHOTO, J.J.M.; AZZONI, C. R.; ICHIHARA, S.M. Contribuição da agricultura e do agronegócio familiar para o PIB do Nordeste. Revista Econômica do Nordeste, v.45, p.136-152, 2014.

IBGE. Instituto Brasileiro de Geografia e Estatística. Pesquisa trimestral de abate de animais. Disponível em: https://sidra.ibge.gov.br/home/abate/brasil. Acesso em: 02 de fevereiro de 2018.

ITO, M.; GUIMARÃES, D.D.; AMARAL， G.F. Impactos ambientais da suinocultura: desafios e oportunidades. BNDES Setorial, v.44 , p.125-156, 2016.
LACERDA, J. R. C.; SOUSA, J. S.; SOUSA, L. C. F. S.; BORGES, M. G. B.; FERREIRA, R. T. F. V.; SALGADO, A. B.; SILVA, M. J. S.; Conhecimento popular sobre plantas medicinais e sua aplicabilidade em três segmentos da sociedade no município de Pombal-PB. Revista: Agropecuária Científica no Semiárido, v.9, n.1, p.14-23, jan-mar, 2013.

LEVIN, J. Estatística Aplicada a Ciências Humanas. 2. ed.. São Paulo: Editora Harbra Ltda, 1987.

LEVINE, D. M.; BERENSON, M. L.; STEPHAN, D. Estatística: Teoria e Aplicações usando Microsoft Excel em Português. Rio de Janeiro: LTC, 2000.

OLIVEIRA, D.V.; FAGUNDES, M.B.B.; SILVA, L.C.; FIGUEIREDO NETO, L.F.; FERNANDES, M.M. A Importância da Suinocultura para a Geração de Emprego e Renda nos Municípios do Estado do Mato Grosso do Sul - Brasil. Espacios, v.37, n.26, p.11-16, 2016.

PEROSSI, I.F.; MACHADO, A.B.; SAMPAIO, A.N.C.E.; ARAUJO, H.C.; GRATON. A.C.; LACERDA, L.H.; POLEGATO, E.P.S. Manejo e destinação ambientalmente adequados de resíduos da suinocultura revisão de literatura. Revista Unimar Ciências, v. 26, n.1-2, p. 1-13, 2017.

ROCHA, L.O.; OLIVEIRA, R.M.; HELLMEISTER FILHO, P.; GOMES, N.A.; CARNEIRO, M.F.; SILVA, O.M.; FERNANDES, L.C. Panorama da criação de aves e suínos caipiras em regiões periurbanas no município de Senador Canedo (GO), Brasil. Investigação Qualitativa em Educação, v.3, p.629-638, 2016.

SANTOS, C.L.A.; SOARES, D.M.A.; ABRANTES, R.S.X.; SANTOS, V.C.; LOIOLA, M.V.C.; SANTOS, E.L.A.; SOUZA, K.A.; LIMA, P.M.F.Suinocultura agroecológica e industrial: nutrição, sistemas de produção e sanidade. Informativo Técnico do Semiárido, v.10, n.2, p.31-36, 2016.

SILVA FILHA, O. L.; BARBOSA, E. J. R.; Lima, A. D; MELO, A. G. P.; MELO FILHO, A.J.; SÁ, M.S.Os produtores de suínos no município de Floresta, Estado de Pernambuco, Brasil. Actas Iberoamericanas de Conservación Animal, v.1, s.1, p. 416-418, 2011.

SILVA, D.E.Desenvolvimento local: alternativas para geração de renda e preservação ambiental em pequenas propriedades rurais. $2015.117 \mathrm{f}$. Dissertação (Mestrado em Desenvolvimento, Tecnologias e Sociedade) - Universidade Federal de Itajubá, Itajubá, 2015. 
ZANELLA, J.R.C.; MORÉS, N.; BARCELLOS, D.E.S.N. Principais ameaças sanitárias endêmicas da cadeia produtiva de suínos no Brasil. Pesquisa Agropecuária Brasileira, v.51, n.5, p. 443-453, 2016. http://dx.doi.org/10.1590/S0100-

204X2016000500004 